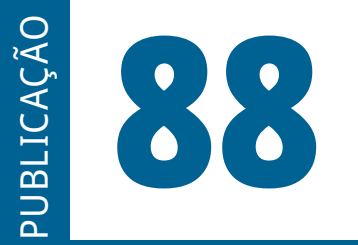

ISSN: 0101-9562

ISSN ELETRÔNICO: 2177-7055

SEQÜÊNCIA

Publicação do

Estudos jurídicos

e políticos

Programa de Pós-Graduação em Direito da UFSC

VOLUME 42 - ANO 2021 
SEQUÊNCIA - ESTUDOS JURÍDICOS E POLÍTICOS é uma publicação temática e de periodicidade quadrimestral, editada pelo Programa de Pós-Graduação Stricto Sensu em Direito da Universidade Federal de Santa Catarina - UFSC.

SEQUÊNCIA - ESTUDOS JURÍDICOS E POLÍTICOS is a thematic publication, printed every four months, edited by the Program in law of the Federal University of Santa Catarina - UFSC.

Versão eletrônica: http://www.periodicos.ufsc.br/index.php/sequencia

A publicação é indexada nas seguintes bases de dados e diretórios/

The Publication is indexed in the following databases and directories:

Base OJS

Base PKP

CCN (Catálogo Coletivo Nacional)

Dialnet

DOAJ (Directory of Open Access Journals)

EBSCOhost

Genamics Journalseek

ICAP (Indexação Compartilhada de Artigos de Periódicos)

Latindex

LivRe!

OJS
PKP
Portal de Periódicos UFSC
Portal do SEER
ProQuest
SciELO
Sherpa/Romeo
Sumarios.org
ULRICH'S
vLex

Ficha catalográfica

Seqüência: Estudos jurídicos e políticos. Universidade Federal de Santa Catarina.

Programa de Pós-Graduação em Direito. n.1 (janeiro 1980)-.

Florianópolis: Fundação José Boiteux. 1980-.

Publicação contínua

Resumo em português e inglês

Versão impressa ISSN 0101-9562

Versão on-line ISSN 2177-7055

1. Ciência jurídica. 2. Teoria política. 3. Filosoia do direito. 4. Periódicos.

I. Universidade Federal de Santa Catarina. Programa de Pós-graduação em

Direito

CDU 34(05)

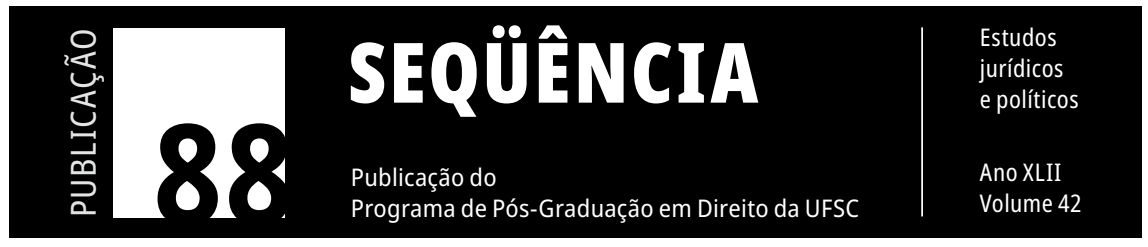




\section{A retórica do direito natural: uma crítica a partir de Friedrich Nietzsche}

\section{The rhetoric of natural law: a critique based on Friedrich Nietzsche}

Luiz Filipe Araújo Alves

Universidade Federal de Viçosa, Viçosa, Brasil

RESUMO: Na tradição ocidental, o direito natural foi o mais duradouro fundamento do próprio direito e da justiça, mesmo que sempre contraposto, complementado ou contestado pelo direito escrito e positivo. Neste sentido, a proposta deste artigo é fazer uma reflexão sobre a transposição, muitas vezes insuspeita, que ocorre de um fundamento metafísico para o mundo a um fundamento metafísico para o direito. Para isso, será apresentada uma leitura crítica do jusnaturalismo a partir da obra de Friedrich Nietzsche, correlacionando-a com uma de suas ideias mais polêmicas, mas também vulgarizada: a morte de deus.

PalaVRas-Chave: Direito Natural - Nietzsche - Retórica.

ABSTRACT: Natural law has been the most enduring foundation of law and justice in western tradition, even if opposed, complemented or challenged by written and positive law. Thus, an approach can be made to the often-unsuspected transposition from a metaphysical foundation of the world to a metaphysical foundation of law. The proposal in this article presents a critical reading of natural law based on the philosophical thought of Friedrich Nietzsche, demonstrating in which manner the philosopher dealt with this subject explicitly and how it is possible to criticize from one of his most controversial, but also vulgarized ideas: the death of god.

KEYWORDS: Natural Law - Nietzsche - Rhetoric. 


\section{INTRODUÇÃO}

Sob o ponto de vista da história do pensamento jurídico, inegavelmente, o direito natural pode ser considerado o fundamento mais duradouro e mais recorrente para o direito e a justiça. As reflexões sobre o jusnaturalismo perpassaram tradições filosóficas e religiosas variadas, dos marcos da épica e da tragédia gregas aos textos teológicos da idade média. Trata-se de uma tarefa hercúlea para qualquer jusfilósofo ou historiador das ideias traçar uma história do direito natural. Uma compreensão histórica do direito natural foi tentada algumas vezes no direito moderno, na tradição alemã do século XIX marcante é a oposição ao direito racional do iluminismo feita na recepção de Kant por Heinrich Ahrens (Ahrens, 1968), já no séc. XX Felix Flückiger (FLüCKIGER, 1954) retoma a problemática de forma histórica, ambas de forte matriz teológica. Ainda na tradição alemã a obra de Heinrich Rommen de 1936, que foi traduzida para o inglês em 1947 (Rommen, 1998), irá impactar a tradição anglo-saxã, além dos estudos já consagrados de Leo Strauss (Strauss, 2009) e John Finnis (Finnis, 2011), mesmo que não histórico-sistemáticos. $\mathrm{Na}$ tradição latina, recentemente encontramos os esforços de Javier Hervada (Hervada, 2006). Mais complexa e original é a leitura de Eric Wolf em o "Problema da Doutrina do Direito Natural” (Wolf, 1964), que através de uma articulação entre teses e corolários apresenta as relações do direito natural com uma abordagem de uma ontologia fundamental do direito em diálogo com a tradição fenomenológica. Esse panorama serve para demonstrar que o direito natural foi e ainda é objeto de grande interesse jusfilosófico.

Todavia, o presente trabalho, por se inserir nos estudos Nietzsche, não pretende fazer nem uma história do direito natural e tampouco uma aplicação da Genealogia dos Valores em relação ao direito natural. $\mathrm{O}$ aspecto teórico importante aqui é verificar em que medida as discussões sobre o direito natural, que sempre estiveram presentes nas reflexões da filosofia do direito, não foram ignoradas pela reflexão 
de Friedrich Nietzsche. Se há uma inegável hegemonia do direito natural em suas diversas modalidades até o século XIX enquanto fundamento da justiça, tal hegemonia só foi abalada após um de seus filhos devorar seu pai, pois o direito codificado propalado pela tradição francesa - inspirado a partir de princípios racionais do jusnaturalismo (Grossi, 2004, p. 87-122.), como Portalis delineou em seu projeto de codificação - acabou sendo o principal responsável pelo declínio do direito natural no plano jurídico. "O direito é a razão universal, a suprema razão fundada sobre a natureza mesma das coisas. As leis são ou devem ser apenas o direito reduzido a regras positivas, a preceitos particulares." (Portalis in Lima Lopes, 2009, p. 210).

O próprio século XIX foi prova deste constante embate contra a ideia de direito natural, pois com o desenvolvimento das diversas matrizes historicistas e relativistas que naquele período surgiram, pouco a pouco, foram abalados também os fundamentos de um direito natural racional, eterno e imutável. Ademais, a importância do jusnaturalismo se mostrou na estrutura de reprodução do conhecimento jurídico enquanto área do conhecimento. Basta relembrar que a cadeira de Direito Natural - ou mesmo de Direito Natural e das Gentes - se manteve central em grande parte das graduações em direito, inclusive no Brasil (Menezes, 1980, p. 252); e o surgimento da filosofia do direito enquanto campo da própria filosofia estava imbricado com o direito natural, como se deu com a agora bicentenária obra de Hegel "Princípios de Filosofia do Direito", cujo subtítulo ignorado em algumas traduções brasileiras deixa claro: "ou Direito Natural e Ciência do Estado em esboço” (Hegel, 1976). A tradução brasileira só contempla o texto de 1820, sem os comentários e notas posteriores (HEGel, 1997).

Por sua vez, o declínio no plano do imaginário jurídico não significa a decadência no plano filosófico, pois o direito natural enquanto ídolo metajurídico ainda tem sua sombra mostrada na caverna, para usar uma metáfora nietzschiana em referência ao aforismo $\$ 108$ de Gaia Ciência: "Deus está morto; mas, tal como são os homens, 
durante séculos ainda haverá cavernas em que sua sombra será mostrada. - Quanto a nós - nós teremos que vencer também a sua sombra!" (Nietzsche, 1999, Vol. 3, p. 467; 2001a, p. 135)․․ Em certo sentido, pode-se dizer que há um eterno retorno do direito natural nos momentos de comoção e crise, como na fórmula utilizada por Heinrich Rommen como título de sua obra "Die ewige Wiederkehr des Naturrechts" publicada em 1936 (Rommen, 1998). Djacir Menezes, demonstra que a sedução jusnaturalista quase predominou nas primeiras discussões sobre os crimes de guerra dos julgamentos de Nuremberg (Menezes, 1980, p. 135-142). Tal ideia de permanência e retomada fora até mesmo utilizada por defensores do direito natural no século XX, como Heinrich Rommen ou Truyol y Serra (Truyol Serra, 1949, p. 15), ou mesmo em estudos de problematização e atualização, como em Leo Strauss (Strauss, 2009) e John Finnis (Finis, 2011). Mesmo que em Leo Strauss haja o esforço de reconstrução de forma mais problemática do que histórica em sentido estrito, que pretende apresentar uma reconciliação do direito natural com a filosofia política.

Francesco Viola, numa consistente síntese do direito natural no século $\mathrm{XX}$, descreve pelo menos três grandes renascimentos do direito natural (Viola in Pattaro; Roversi (Org.), 2016, p. 5). Um primeiro no alvorecer do século enquanto insatisfação com os positivismos jurídicos do século XIX, ou seja, como reação à jurisprudência dos conceitos ou à própria escola da exegese. Este primeiro retorno marcado principalmente por uma influência de doutrinas cristãs do direito natural e um ressurgimento de doutrinas neotomistas. Um segundo renascimento decorrente das violações à dignidade humana na segunda guerra mundial pelos regimes totalitários, que não foram

NOTA: Na medida do possível serão referidas as obras de Nietzsche a partir da indicação dos parágrafos [\$] da obra, pois favorece a comparação independentemente da edição. Assim, indicaremos primeiro a edição completa alemã [Kritische Studienausgabe - KSA], logo em seguida, quando houver, a edição em língua portuguesa e adicionalmente referência ao parágrafo da respectiva obra quando já não estiver explícito no corpo de texto. 
evitadas pelo direito positivo, e assim o direito natural retornaria para que essas violações não ocorressem novamente. Um terceiro decorrente do papel que os direitos humanos assumiram nos regimes constitucionais, assumindo mais uma vez uma crise do positivismo jurídico e a necessidade de uma volta a fundamentos morais para o direito. Três renascimentos num longo século que demonstram a ideia de Rommen quanto ao eterno retorno do direito natural. Se ampliarmos a discussão para o campo filosófico contemporâneo, a problematização do direito natural ganha maiores contornos na tensão entre fé e conhecimento. Quanto a isso, com um caráter que renderá discussões nos próximos anos não poderá ser ignorada sobre a temática a última obra publicada de Jürgen Habermas: "Também uma história da filosofia", com o primeiro volume intitulado "A constelação ocidental de fé e conhecimento" e o segundo volume intitulado "Liberdade Racional: traços do discurso sobre fé e conhecimento. Especialmente o capítulo do primeiro volume "Cenários de crise e histórias de decadência nas grandes teorias filosóficas do século XX" [Krisenszenarien und Verfallsgeschichten in philosophischen Großtheorien des 20. Jahrhunderts] (Habermas, 2019, p. 40-74).

Por outro lado, não seria um excesso afirmar que o direito natural, com todo seu arcabouço metafísico, ainda se encontra impregnado nas categorias jurídicas mais variadas: na pessoa natural da civilística, na natureza jurídica dos institutos, na verdade real dos processualistas, nos princípios gerais do direito e até mesmo nos chamados direitos humanos, que certamente hoje se encontram enquanto fundamentos do direito, do estado e da ordem internacional. Do mesmo modo, assim o foi com o direito natural já no início da modernidade em Francisco Vitória, Francisco Suarez, Bartolomeu de Las Casas, Hugo Grotius e tantos outros jusnaturalistas (HervadA, 2006, p. 55-101). Estas e outras hipostasias do direito foram postas enquanto fundamento primeiro e último da juridicidade e normatividade.

Entretanto, o objetivo neste momento será apresentar as discussões que Nietzsche teve contra esse problema central da filosofia 
do direito: o direito natural. Em certas passagens, o filósofo refere-se diretamente ao tema, bem como algumas ilações críticas podem ser construídas entre o pensamento a marteladas e os ídolos do jusnaturalismo. Para tanto, apresentar-se-ão algumas referências diretas do filósofo à questão do direito natural e ao problema correlato da filosofia do seu tempo na chamada justiça eterna, para quem a Filosofia do Direito que "mal havia saído das fraldas" (Nietzsche, 1999, Vol. 11, p. 697), como satiriza o filósofo em um fragmento póstumo. Neste percurso crítico algumas abordagens clássicas do direito natural serão apresentadas dentro deste panorama da história da filosofia do direito.

Deste modo, a primeira parte do texto se dedicará à reconstrução de algumas bases filosóficas do pensamento de Nietzsche para que se possa compreender adequadamente a colocação do problema do direito natural. Nisto será importante compreender o sentido do dito a "morte de deus", tão citado e tão pouco compreendido, e como esta reflexão se insere numa chave de leitura retórica do pensamento de Nietzsche, que por sua vez possui relação direta com o problema do perspectivismo enquanto uma primeira contraposição aos absolutismos da razão. Na segunda parte do texto trata-se da relação entre a morte de deus e a inocência do devir dentro do pensamento nietzschiano e como ambas ideias estão relacionadas com um alívio de absolutos.

Para pensarmos a partir da expressão "Entlastung von Absoluten" de Odo Marquard. Entlastung que literalmente pode ser traduzida como descarga ou descarregamento, mas semanticamente como alívio, e até libertação, e possui pelo menos dois sentidos na tradição intelectual. Um primeiro para uma linhagem sócio-antropológica entre Arnold Gehlen e Niklas Luhmann (LuHmanN, 1970, p. 96) quanto à redução de complexidade através do descarregamento em subssistemas ou por acoplamentos estruturais, e outra mais cético-antropológica que está em Odo Marquard (Marquard, 2000, p. 108-120.) quanto a sua leitura de Hans Blumenberg, onde esse alívio através do descarregamento se dá no plano da linguagem, como nas metáforas e nos conceitos, como nas mitologias e religiões. Assim, será possível discorrer sobre o que 
seria a morte do direito natural a partir de marcos nietzschianos. $\mathrm{Na}$ conclusão apresenta-se as posições da retórica jurídica que também dialogam com Nietzsche quanto às possibilidades de resposta a ausência de fundamento metafísico para o direito.

\section{PERSPECTIVISMO, GENEALOGIA E A MORTE DE DEUS: UM OCASO DA METAFÍSICA}

A confrontação de fundamentos metafísicos ou pretensões de encontrar alguma essência transcendente às coisas é um primeiro aspecto que deve ser analisado no pensamento de Nietzsche em relação a esta temática. Aqui reside a importância da Genealogia enquanto dimensão crítica das ideias na história ao revelar a ausência de fundamento absoluto a estes valores morais em sua atemporalidade. Em Nietzsche certos aspectos do Perspectivismo fazem-se presentes enquanto modo experimental de um filosofar crítico sobre a realidade e o conceito de verdade.

Tais aspectos da filosofia nietzschiana raríssimas vezes foram pensados dentro da filosofia do direito e da teoria do direito no Brasil. Um dos grandes exemplos da presença e contribuição do pensamento de Nietzsche a essa discussão seria na matriz filosófica de uma Filosofia Retórica, como entre nós difundida por João Maurício Adeodato. Esta reflexão encontra similitudes com as concepções perspectivísticas sobre o conhecimento e sua intrínseca relação com função constitutiva da linguagem em Nietzsche. O jusfilósofo brasileiro, ao explicitar o marco teórico de sua filosofia do direito, apresenta algo muito próximo dos esforços empreendidos até aqui neste trabalho para correlacionar o pensamento de Nietzsche, no que tange ao Perspectivismo, à verdade e ao conhecimento:

O que aqui se pensa como o caráter constitutivo da realidade, processado pela linguagem, é denominado retórica material, uma idéia inspirada pela leitura da obra de Friedrich Nietzsche, 
sugerida a princípio por Ottmar Ballweg e aqui transformada em marco teórico. A retórica material é assim o primeiro plano da realidade, a maneira como os humanos constroem o próprio ambiente no qual ocorre a comunicação. Ela constitui a própria condição antropológica de ser humano, é o único dado ontológico que pode ser associado ao universo do homo sapiens, um ser que só percebe o meio lingüísticamente, até no diálogo consigo mesmo que forma seu pensamento. (ADEODATO, 2010, p. 40. Publicada posteriormente como livro, $c f$. Adeodato, 2014, p. 47)

Uma abordagem como esta reconhece acima de tudo o caráter retórico da linguagem. Não se trata da retórica instrumentalizada em ferramentas de estilo e eloquência enquanto ars oratoria, posição esta já criticada por Nietzsche no século XIX quando já se tentava compreender a retórica num catálogo frio de figuras de linguagem (Nietzsche, 1995, p. 413-502). A retórica pode e deve ser pensada enquanto abordagem para se pensar a linguagem e os limites para o conhecimento (Ballweg in Kopperschmidt; Schanze (Org.), 1994, p. 230). Os elementos de crítica retórica da linguagem e da própria retórica foram apresentados tanto nas Vorlesungen sobre retórica de 1872-74, como em outros escritos póstumos como Sobre Verdade e Mentira no sentido extramoral. Relação esta que Hans Blumenberg sintetizou muito bem em sua obra Trabalho sobre o Mito: "Pois a retórica constitui a essência da filosofia de Nietzsche" (Blumenberg, 2006, p. 272).

Tal elemento retórico apresenta a própria linguagem enquanto um relato mítico sobre o que comumente é chamado de verdade pela tradição. João Maurício Adeodato (AdeodAto, 2010, p. 97), em sua exposição sobre o caráter retórico da linguagem e do direito, apoia-se em Nietzsche nesta questão: “Todos os conceitos nos quais se compõe semioticamente um processo inteiro escapam à definição; definível é somente aquilo que não tem história" (Nietzsche, 1999, Vol. 5, p. 317; 2001b, p. 68 [Genealogia da Moral, II, \$13]). Neste sentido, também dentro do procedimento genealógico a compreensão retórica 
da linguagem em Nietzsche leva a uma quebra de ideia de finalidade ou teleologia, seja da história ou dos valores, porquanto, se coloca em uma oposição às escatologias da história. Posição está que também é reafirmada por Antônio Edmilson Paschoal (PAschoAl, 2015, p. 18).

Esta quebra de uma visão essencializada do mundo levaria Nietzsche a concordar com um de seus leitores, Emil Cioran: "A história não passa de um desfile de falsos Absolutos, uma sucessão de templos elevados a pretextos, um aviltamento do espírito ante o Improvável" (Cioran, 2011, p. 10). Compreensão esta que acusa exatamente a fábula entre mundo real e mundo aparente já enfatizada por Nietzsche no título de um dos capítulos de Crepúsculo dos Ídolos: "Como o 'mundo verdadeiro' se tornou finalmente fábula - A história de um erro" (Nietzsche, 1999, Vol. 6, p. 80; 2006, p. 31) O próprio Cioran, relembrando o fechamento do mundo de Clemant Rosset, reafirma que não é mais possível a dicotomia entre aparente e verdadeiro, isto se dá especialmente a partir de Nietzsche e a questão da Morte de Deus (Cioran, 2011, p. 10).

A temática da Morte de Deus é uma das questões mais vulgarizadas do pensamento de Nietzsche, mas que se encontra em profunda relação com o nosso problema quanto ao direito natural e aos fundamentos metafísicos para a realidade. A imagem sai pela boca de Zaratustra, mas foi utilizada pela primeira vez em Gaia Ciência no aforismo chamado "O homem desvairado" [Der tolle Mensch ${ }^{2}$ ] (Nietzsche, 1999, Vol. 3, p. 480-481; 2001b, p. 147-148. [Gaia Ciência, \$125]). Destaca-se que Nietzsche não foi primeiro a utilizar a expressão. Hegel fez uso da mesma para se referir à tragédia grega e aos impactos até mesmo na filosofia política. Neste sentido, destaca Robert R. Williams em obra dedicada à comparação, sobre a Morte de Deus, entre Hegel e Nietzsche (Williams, 2012. p. 292). Para além de uma leitura meramente reducionista de um ateísmo em Nietzsche,

Vale mencionar que o adjetivo toll em alemão pode comportar a tradução como espetacular ou terrível. 
não se trata de uma referência direta ao deus pessoal das religiões monoteístas. Trata-se muito mais de uma discussão a partir da ideia ocidental representada em Deus enquanto um fundamento do mundo, e, portanto, da própria realidade. Como bem explica Marco Antonio Casanova: "Deus não é apenas uma entidade religiosa que se mantém no âmbito de realização de nossas crenças, ele também determina o modo de compreensão do que efetivamente é." (CASAnOva, 2003, p. 193). Nietzsche está destacando que em seu tempo, que ainda é o nosso tempo, não é mais possível articular a realidade a partir de um fundamento metafísico, queira chamá-lo de deus, natureza ou cosmos. "Todos os homens precisam aceitar o fato de serem os assassinos de Deus porque todos se encontram agora sob o signo de uma decisão fundamental do pensamento: de uma nova determinação do real, de uma história mais elevada do que toda história até aqui; e isto justamente por nascer após a dissolução do que havia de mais elevado até aqui." (Casanova, 2003, p. 198).

A Morte de Deus não é um ato constitutivo a partir da afirmação nietzschiana, não é um assassínio premeditado; pelo contrário, é a declaração de que não é mais possível conceber o mundo a partir de um princípio metafísico unificador, mas que ao mesmo tempo cinde o mundo entre aparência e realidade (CAsanova, 2003, p. XIII), como foi recepcionado através da tradição platonista, e posteriormente teológica nos diversos monoteísmos por meio das compreensões transmundanas sobre a vida e o valor. Porquanto esta dicotomia implicaria assumir que esta realidade efetiva é deficitária em algum sentido à outra realidade, mais perfeita, mais divina.

O ponto central para Nietzsche é que não há esse déficit ontológico. Não existe o melhor dos mundos possíveis. Efetivamente só existe este mundo, em suas contingências, belezas e tragédias. Como muito bem esclarece Marco Antônio Casanova:

O que Nietzsche procura empreender a partir da supressão da dicotomia entre sensível e suprassensível aponta diretamente para uma redução de tudo a este espaço mundano que é o 
nosso. De certa forma, de uma maneira muito peculiar e estranha, Nietzsche se mostra a partir de certo momento como um monista. Melhor: ele descobre o caráter monista do campo existencial e dá voz a um dos traços mais peculiares de uma corrente poderosa do pensamento contemporâneo que envolve pensadores como Max Scheler, Edmund Husserl, Martin Heidegger, Hans Georg Gadamer e Hans Blumenberg entre muitos outros. (CASANOva, 2013, p. 186)

Portanto, percebe-se claramente em Nietzsche uma desconstrução de fundamentações dualistas do mundo, entre sensível-suprassensível, real-ideal, verdadeiro-aparente. Todo ideal e todo idealismo são vistos com desconfiança por Nietzsche, conforme também a leitura heideggeriana. Esta é, por exemplo, a própria leitura de Martin Heidegger: "O dito "Deus morreu" significa: o mundo supra-sensível está sem força actuante. Ele não irradia nenhuma vida. A metafísica, isto é, para Nietzsche, a filosofia ocidental compreendida como platonismo, está no fim. Nietzsche compreende a sua filosofia própria como o contra-movimento contra a metafísica, isto é, para ele, contra o platonismo." (Heidegger, 2002, p. 251). Neste contexto, a ideia de um direito natural enquanto instância regulativa da ordem jurídica, política e social é inteiramente descabida nas compreensões do filósofo. Os fenômenos normativos não possuem um pressuposto a priori, um fundamento transcendental, mas acontecem e ganham sentido na processualidade histórica e na significação retórica da linguagem enquanto manifestações da realidade em seu constante e irremediável devir.

A morte de deus é uma construção metafórica para o diagnóstico de uma fase da história da metafísica. Não se trata de um ateísmo imperativo, pois um deus ou deuses ainda serão objetos da crença e do imaginário mítico, as religiões nascerão e perecerão enquanto durar a leitura humana das histórias na história. Todavia, a ideia e os laços com a divindade não seriam mais capazes de articular a experiência com o mundo e com si mesmo como fora no passado. Odo Marquard traz em Elogio do Politeísmo [Lob des Polytheismus] uma compreensão 
interessante - que está na base de várias teorias do mito no século $\mathrm{XX}$-, existirão mitos enquanto existir humanidade, pois os mitos são histórias e narrativas sobre o humano e sobre um "mundo narrado", funcionando como uma necessidade. "Não existe nada sem mitos: narrare necesse est". Todavia, nessa inevitabilidade do mítico é desejável um mundo polimítico, um politeísmo, porquanto o monomítico e o monoteísmo exigem apenas um mundo e um absoluto (MARQUARD, 2015, p. 51-53). Do mesmo modo que o direito natural não é capaz de articular a normatividade ou mesmo seu fundamento, como fora também no passado. Apesar de que as sombras de deus e do direito natural ainda estão refletidas na caverna do imaginário humano.

\section{A MORTE DE DEUS E A INOCÊNCIA DO DEVIR EM NIETZSCHE}

Por outro lado, a assunção da Morte de Deus tem consequências das mais variadas no plano da filosofia de Nietzsche e seus leitores. Uma vulgarização pós-moderna recepcionou a ideia de deus está morto com uma só conclusão: "portanto, tudo é permitido" com dissolução de todo fundamento da moral, uma espécie de radicalização da máxima da Ordem dos Assassinos em Genealogia da Moral (Nietzsche, 1999, Vol. 5, p. 399; 2001b, p. 138. [Genealogia da Moral, III, §24]). Para Heidegger e tantos outros leitores de Nietzsche (CAsanova, 2013, p. 186), a Morte de Deus traz desafios ainda maiores para a filosofia ao ser necessário rearticular as forças que movem o homem no plano da existência, pois o deicídio promovido pelo ocidente retiraria todas as possibilidades sobre um fundamento para a existência (Nietzsche, 1999, Vol. 3, p. 480-481; 2001a, p. 147-148 [Gaia Ciência, \$125]).

Entretanto, a Morte de Deus a partir uma leitura interna da obra de Nietzsche apresenta duas reflexões mais complexas: o Niilismo e a Inocência do Devir, enunciada poeticamente nas metamorfoses do Camelo - Leão - Criança (Nietzsche, 1999, Vol. 5, p. 29; 2011, p. 25. Assim Falou Zaratustra, I, "Das três metamorfoses"). O problema do 
Niilismo é um dos temas mais complexos dentro da reflexão nietzschiana, mas preliminarmente podemos descrever que para Nietzsche o Niilismo é a desvalorização de todos os valores importantes até agora, ou de outro modo, o reconhecimento de uma crise sem precedentes para o fundamento do mundo; para Nietzsche nada estaria imune a este sinistro hóspede (Nietzsche, 1999, Vol. 12, p. 125. KSA 12, 2 [127]) que estava à porta quando se falava em seu tempo e para nosso tempo.

Durante toda a história foram predominantes visões de mundo que não suportavam um mundo imperfeito. A moral pós-platônica quer correição, perfeição. Por isso Nietzsche sempre elogiou a compreensão dos gregos arcaicos ao assumirem o caráter trágico da existência em seus mitos. O homem moral não quer um mundo imperfeito, quer um mundo para que possa se ajoelhar, quer olhar o devir para admirar algo para além do devir. Nisto o longo aforismo que abre a Gaia Ciência - "Os mestres da finalidade da existência" - mostra que o devir carece de maldade ou bondade, ele está além do bem e do mal (NiETzsche, 1999, Vol. 3, p. 369-372; 2001a, p. 51-54. [Gaia Ciência, \$1]). Todavia, o homem sempre quis ver algo de moral na vida e, pode-se acrescentar, na natureza. Para Nietzsche o devir não é por si mesmo maculado, e é por si nenhuma causalidade e finalidade. Porém, tais mestres não conseguem compreender a Inocência do Devir, já que sempre tentaram dar uma causa e finalidade moral para vida.

A vida deve ser amada, pois — ! O ser humano deve promover a si e ao próximo, pois - ! E quaisquer que sejam e venham a ser futuramente esses Deves e Pois! Para que tudo o que ocorre necessariamente e por si, sempre e sem nenhuma finalidade, apareça doravante como tendo sido feito para uma finalidade e seja plausível para o ser humano, enquanto razão e derradeiro mandamento - para isso entra em cena o mestre da ética, como mestre da finalidade da existência; (...) (Nietzsche, 1999, Vol. 3, p. 371; 2001a, p. 53. [Gaia Ciência, \$1])

Nietzsche com sua filosofia da inocência do devir pretende uma liberação pessoal das categorias morais dominantes no ocidente. Mesmo 
que se deva assumir que neste intento o filósofo não tenha criado uma teoria sistemática para refutar a teleologia platônica-aristotélica-cristã. Tal abordagem acaba sendo mais um experimento intelectual do filósofo trágico, mas em completa coerência com suas proposições éticas como do Além-do-homem e do Eterno-Retorno do Mesmo.

Tal questão foi exaustivamente estudada por Karl Löwith (LöwITH, 1997, p. 27-107) na intrínseca relação entre a Morte de Deus, a Inocência do Devir e Além-do-homem, compreendendo o Eterno Retorno como ideia unificadora da filosofia de Nietzsche sobre o problema do Niilismo na transformação moral do "Tu deves" para "Eu quero", para finalmente o imperativo ético da criança "Eu sou". A criança em sua inocência seria uma metáfora para o devir e o conhecimento deste para a busca de novos caminhos na moral, o que dentro da filosofia nietzschiana perpassaria pela Transvaloração dos Valores e a realização do Além-do-Homem. Neste sentido, apesar das divergências ideológicas com Martin Heidegger, especialmente na questão do nazismo, os dois filósofos trabalham questões muito próximas nestes temas nietzschianos, mesmo que sem tanta ênfase na Vontade de Poder.

O grande aspecto que se deve destacar neste temário sobre a inocência do devir é a sua relação com as tentativas ao longo da história ocidental ao pretender uma relação entre causa, efeitos e finalidades da existência. Neste ponto Erwin Hufnagel (Hufnagel in Niemeyer, 2012, p. 147-149) esclarece essa relação ao dizer que o conceito de devir pretende nos liberar da crença no Logos, esta obsessão pelo sentido e pela liberdade, especialmente na tradição ocidental submetida à ideia de justiça. Como para os gregos trágicos, os processos do devir, da criação e da destruição, esvaziam a realidade de todo o sentido fundamental ou finalístico e não conhecem nem culpa e nem justiça. O homem sempre buscou causas e finalidades, mesmo com novas explicações sobre os fenômenos a partir dos marcos científicos - que jamais deveriam ser absolutos por estarem submetidos epistemologicamente à falseabilidade (POPPER, 1978). Como também assevera João 
Maurício Adeodato, mesmo com uma nova concepção do universo após Copérnico, as etiologias e escatologias permanecem na visão moderna da história, ainda que dominada pelos sucessos da ciência, mas mesmo assim contrária ao humanismo e ao estudo da retórica (Adeodato, 2010, p. 47).

Assim, é possível afirmar que uma Filosofia Retórica se alinha à Genealogia dos Valores de Nietzsche, pois é contra qualquer etiologia por não acreditar em uma teoria sobre a origem das coisas estribada no conceito de causalidade. Assim como também se alinha a uma Filosofia Histórica e à compreensão de Inocência do Devir de Nietzsche, pois é contrária a qualquer escatologia ao não acreditar que a história tenha um fim ou finalidade, que por sua vez se relaciona com um ceticismo a respeito das causas (AdeOdATo, 2010, p. 47).

\section{A MORTE DO DIREITO NATURAL}

Com tais explicações é possível retornar agora ao problema do direito natural para Nietzsche. Deve-se destacar que, enquanto referência textual, o filósofo usa a expressão direito natural [Naturrecht] apenas uma vez em toda sua obra publicada. De todas as lições extraídas anteriormente é certo que para o filósofo não há nem justiça natural, nem injustiça natural, pois não há como dotar a natureza de uma significação moral como se pretendeu ao longo da história. Da forma que o direito natural foi compreendido não haveria, portanto, como se pensar numa justiça natural, pois:

Vaidade como posterior rebento do estado não social. — Dado que os homens, com vistas à sua segurança, puseram-se como iguais uns aos outros para a fundação da comunidade, mas tal concepção vai contra a natureza do indivíduo e é algo forçado, no fundo, ocorre que novos rebentos do antigo impulso à preponderância se afirmam, quanto mais a segurança geral é garantida: na demarcação das classes, na reivindicação de 
dignidades e privilégios profissionais, na vaidade em geral (maneiras, indumentária, linguajar, etc.). Tão logo a comunidade volta a sentir-se em perigo, os mais numerosos, que no estado de sossego geral não podiam estabelecer sua preponderância, fazem ressurgir o estado de igualdade: os absurdos direitos especiais e vaidades desaparecem por algum tempo. Mas, se a comunidade desmorona inteiramente, se tudo cai na anarquia, imediatamente irrompe o estado de natureza, a desigualdade inconsiderada e brutal, como sucedeu em Córcira, segundo o relato de Tucídides. Não há direito natural nem injustiça natural. (Nietzsche, 1999, Vol. 2, p. 563; 2008, p. 184. [Andarilho e sua sombra, \$31]) [Grifo nosso]

Neste sentido, o direito e a justiça são demasiadamente humanos e muito distantes de ilusões metafísicas na seara do pensamento nietzschiano. Como enuncia Patrick Wotling: "O filósofo pretende, por sua vez, atribuir a inocência ao vir a ser, de forma que, ao pensar o verdadeiro sentido da justiça, seja possível promover uma defesa da realidade contra seus acusadores" (WotLing, 2013, p. 207). Neste sentido, seria possível uma crítica à justiça na concepção tradicional da filosofia do direito para se pensar uma construção afirmativa da justiça de forma genealógica e dessencializada dentro dos fins deste trabalho. Contra a posição essencialista, Nietzsche é bastante claro na exposição em Genealogia da Moral:

Falar de justo e injusto em si carece de qualquer sentido; em si, ofender, violentar, explorar, destruir não pode naturalmente ser algo "injusto", na medida em que essencialmente, isto é, em suas funções básicas, a vida atua ofendendo, violentando, explorando, destruindo, não podendo sequer ser concebida sem esse caráter. (Nietzsche, 1999, Vol. 5, p. 312; 2001b, p. 64-65. [Genealogia da Moral, II, \$11])

É importante neste momento fazer um esclarecimento sobre a ambivalência da questão da natureza na obra de Nietzsche. Como apresentado, foi desconstruída a ideia de uma valoração intrínseca de 
bem e mal da natureza, ou de uma moralidade natural. Todavia, em alguns momentos em Nietzsche há o destaque para o papel da terra e da natureza em sua filosofia. Mesmo que não haja explicitamente uma oposição entre natureza e cultura, há uma clara tensão entre elas nas reflexões do filósofo. Em relação ao naturalismo, Rogério Lopes ilustra muito bem o panorama destes estudos:

A filosofia contemporânea de língua inglesa é fortemente marcada pelo debate em torno do naturalismo. Pode-se dizer que a maior parte dos filósofos que pertencem a esta tradição está, de um modo ou outro e em diferentes níveis de radicalidade, comprometida com alguma versão da tese naturalista, enquanto a minoria divergente se esforça para formular uma tese alternativa que não a faça parecer adepta de alguma entidade sobrenatural ou disposta a menosprezar o enorme sucesso e prestígio acumulado pelas ciências empíricas ao longo da modernidade. (Lopes, 2001, p. 301)

A leitura naturalista de Nietzsche possui ecos até mesmo na discussão sobre justiça no filósofo, como o livro de Peter Sedgwick: "Nietzsche's justice: naturalism in search of an ethics" (SEDGwICK, 2013). Obra que foi dedicada a Richard Schacht um dos principais pesquisadores do naturalismo em Nietzsche que afirma: "Há tempos que considero que Nietzsche foi um pensador "naturalista" em termos filosóficos, que dispôs de uma agenda filosófica significativa que se torna mais compreensível se entendida nestes termos" (SCHACHT, 2011, p. 35-75).

De todo modo, para uma discussão quanto ao direito natural a partir de Nietzsche, faz-se necessária uma distinção para que não se confunda a oposição aos jusnaturalismos com o naturalismo nietzschiano. O tema tem pertinência tanto pela tentativa de naturalização da moral em Nietzsche, no sentido de se opor a entes metafísicos que a fundamentam, quanto pelo grande interesse do filósofo pelas ciências naturais de seu tempo e suas relações com a filosofia. Relação esta que também tem suas objeções, pois isso não significaria jamais submeter 
a filosofia às ciências. Veja-se o aforismo posto sobre o tema: "O que caracteriza o século XIX não é a vitória da ciência, mas a vitória do método científico sobre a ciência." (Nietzsche, 1999, p. 442. KSA 13, 15[51]). Pode-se perceber que teses nietzschianas como Perspectivismo e Vontade de Poder tiveram relações dadas pelo próprio Nietzsche a partir de teses científicas de seu tempo, como nos físicos Ernst Mach e Roger Boscovich (EMden, 2014).

Pode-se assim retornar às oposições de Nietzsche à natureza enquanto um fundamento para a moral, e consequentemente para o direito e a justiça. Nietzsche destaca a "indiferença grandiosa da natureza em relação a bem e mal" quanto às ações morais; logo depois continua em afirmação que sintetiza sua oposição ao tema: "Nenhuma justiça na história, nenhuma bondade na natureza: por isso, o pessimista, caso ele seja um artista, segue in historicis para lá onde a ausência da justiça mesma se mostra ainda com uma ingenuidade grandiosa, onde precisamente a perfeição se expressa..." (Nietzsche, 1999, Vol. 12, p. 481. KSA 12, 10 [52]). Mesmo em sua obra publicada anteriormente ao fragmento, Nietzsche desfere duro ataque a esta antropomorfização da natureza em relação à moral:

A boa e a má natureza. - Primeiro os homens projetaram-se na natureza: em toda parte viram a si mesmos e seus iguais, isto é, suas características más e caprichosas, como se estivessem escondidas entre nuvens, temporais, animais de rapina, árvores e plantas: naquele tempo inventaram a "natureza má". Depois veio a época em que novamente se imaginaram fora da natureza, a época de Rousseau: estavam tão fartos uns dos outros, que quiseram possuir um canto a que não chegasse o homem e seu tormento: inventaram a "natureza boa". (Nietzsche, 1999, p. 29; 2001, p. 24. [Aurora, \$17])

Todavia, mais enfática é a posição de Nietzsche em Crepúsculo dos Ídolos quando dedica um capítulo da obra, mesmo que pequeno, ao que chama de "Moral como antinatureza" onde destaca exatamente o contrário do que a maior parte da tradição filosófica defendera até 
então: a natureza não possui nenhuma relação moral em si, muito menos a inspirar as ações morais dos homens; ao contrário, a moral se mostrou até mesmo como antinatural. Mas já em Além de Bem e do Mal o filósofo satiriza os moralistas quanto à incompreensão da "natureza", pois viram apenas aquilo que lhes era interessante: "Não parece haver, entre os moralistas, um ódio à floresta virgem e aos trópicos? (...) Mas por quê? Em favor das 'zonas temperadas'? Em favor dos homens temperados? Dos homens 'morais'? Dos medíocres? —” (Nietzsche, 1999, Vol. 5, p. 117; 2005, p. 95-96. [Além do Bem e do Mal, \$197]).

No referido capítulo de Crepúsculo dos Ídolos, o filósofo enuncia o princípio de moral como antinatureza. Tal questão está relacionada com uma inversão do valor moral da natureza; contrariamente a esta antiga tese, a verdadeira moral da vida é uma naturalização da moral, no sentido da natureza como força transbordante, como impulso, como Vontade de Vida, Nietzsche afirma:

- Darei formulação a um princípio. Todo naturalismo na moral, ou seja, toda moral sadia, é dominado por um instinto da vida - algum mandamento da vida é preenchido por determinado cânon de "deves" e "não deves", algum impedimento e hostilidade no caminho da vida é assim afastado. A moral antinatural, ou seja, quase toda moral até hoje ensinada, venerada e pregada, volta-se, pelo contrário, justamente contra os instintos da vida - é uma condenação, ora secreta, ora ruidosa e insolente, desses instintos. Quando diz que "Deus vê nos corações", ela diz Não aos mais baixos e mais elevados desejos da vida, e toma Deus como inimigo da vida... O santo no qual Deus se compraz é o castrado ideal... A vida acaba onde o "Reino de Deus" começa... (Nietzsche, 1999, Vol. 6, p. 85; 2006, p. 36. [Crepúsculo dos Ídolos, Moral como antinatureza, $\$ 4]$ )

Apenas para retomar este aspecto em sua relação com uma justiça vinculada ao direito natural, há nestes escritos de juventude o problema da justiça Eterna, como em Nascimento da Tragédia, 
\$25: "segundo a lei da eterna justiça" em relação às forças dionisíacas. Neste sentido, Nietzsche está ainda profundamente influenciado pelas compreensões de justiça e princípio do mundo a partir das reflexões dos pré-socráticos - como Heráclito e Anaximandro - para quem a justiça é também um princípio de ordem da totalidade das coisas. Todavia, Nietzsche negou veementemente tal justiça eterna, tema que foi herdado da filosofia schopenhaueriana que influenciou os textos de juventude. Primeiramente, veja-se a acepção dada pelo pessimista de Frankfurt em O Mundo como Vontade e como Representação:

Se os homens, tomados como um todo, não fossem tão indignos, então seu destino, também tomado como um todo, não seria tão triste. Nesse sentido pode-se dizer: o mundo mesmo é o tribunal do mundo. Pudesse alguém colocar toda a penúria do mundo em UM prato da balança, e toda a culpa no outro, o fiel permaneceria no meio. (SChopenhauer, 2005. p. 415-416)

Neste sentido, Renato César Cardoso esclarece que a justiça eterna para Schopenhauer é "esse equilíbrio ontológico, no qual toda injustiça cometida é, também, e ao mesmo tempo, castigo sofrido" (CArdoso, 2008. p. 117). Trata-se da velha imagem schopenhaueriana da Vontade que morde sempre a própria carne, o sofrimento que ela inflige é sempre idêntico ao sofrimento que é infligido aos homens e a todos os objetos plano da Representação. Ainda sobre o tema, explana Felipe Durante:

A justiça eterna independe das instituições humanas e não está submetida ao acaso e ao engano, não sendo, dessa forma, incerta nem oscilante, mas infalível, firme e certa. Ela não requer a mediação do tempo, do espaço, e da causalidade para compensar um ato maldoso, através de consequências ruins. Dessa forma, ela independe da experiência. Ademais, apesar de ela reger o mundo, isso não significa que ela balanceia uma injustiça cometida (ausgeübten Unrechts) em um lugar com um sofrimento em outro lugar: nela, a punição tem de ser tão ligada à injúria que ambas se tornam unas. (Durante, 2012, p. 36) 
Nietzsche claramente recusa a ideia schopenhaueriana de justiça eterna. Em Humano, demasiado humano, Nietzsche escreve enfaticamente sobre os pretensos graus de verdade para o homem: "Não há justiça eterna [es gibt keine ewige Gerechtigkeit]" (Nietzsche, 1999, Vol. 2, p. 73; 2001d, p. 56. [Humano, demasiado humano I, \53]). Assim como recusa igualmente a ideia de justiça poética que reintroduz um deus ex machina (Nietzsche, 1999, Vol. 1, p. 68; 1999a, p. 66). Não há lugar para a justiça cósmica ou a justiça divina no pensamento de Nietzsche, simplesmente porque, como diz o aforismo 109 da Gaia Ciência: "o caráter geral do mundo é (...) caos por toda eternidade" (Nietzsche, 1999, p. Vol. 3, p. 467; 2001a, p. 136 [Gaia Ciência, \$109]). Como bem destaca Blaise Benoit: "O cosmos como reino da ordem, da beleza e da finalidade é suplantado pelo caos: o que reina no mundo é, pois: "a ausência de ordem, articulação, forma, beleza, sabedoria e de todos nossos antropomorfismos estéticos qualquer que seja o nome que dermos" (Benoit, 2010, p. 58).

Portanto, não há uma justiça cósmica ou justiça divina no pensamento de Nietzsche, pois ambas estão apoiadas em pretensões de verdades absolutas e atemporais, do mesmo modo que o direito natural em toda tradição antiga e medieva. Posição esta que também concorda Blaise Benoit (Benoit, 2010, p. 58). Nietzsche de certa forma até relaciona o direito natural monoteísta com as perspectivas politeístas: "No politeísmo estava prefigurada a humana liberdade e variedade de pensamento: a força de criar para si olhos novos e seus, sempre novos e cada vez mais seus; de modo que somente para o homem, entre todos os animais, não existem horizontes e perspectivas eternas" (Nietzsche, 1999, Vol. 3, p. 491; 2001ª p. 157. [Gaia Ciência, \$143). $\mathrm{Na}$ modernidade houve apenas um aprofundamento da natureza universal, da razão divina, para uma razão natural e racional do homem, pois como na significativa imagem de Hugo Grócio: o direito natural existiria mesmo se deus não existisse [etiamsi daremus non esse Deum].

Neste aspecto, a leitura da tradição jusfilosófica, apesar dos erros comuns sobre o pensamento de Nietzsche ou sua radicalização de 
um poder desmedido, equivoca-se apenas parcialmente em relação a Nietzsche. A acertam os autores da tradição quando se referem à origem de todo direito numa relação de poder; todavia, equivocam-se quanto às consequências desse poder. Por exemplo, Alfred Verdross (Verdross, 1962, p. 263), ainda se baseando especialmente na "obra" Vontade de Poder, acerta o diagnóstico quanto à impossibilidade de se pensar o direito natural como fundamento da ordem jurídica na obra de Nietzsche, simplesmente reduzindo-o a uma reflexão igual à de Hobbes e Spinoza. Apesar de Nietzsche estar bem acompanhado por dois mestres da filosofia política moderna, escapa a Verdross e a tantos outros a reflexão de que as dimensões do direito e da justiça não se reduzem a um positivismo legalista ou político. Outro exemplo mais contemporâneo se encontra no jusfilósofo lusitano Paulo Ferreira da Cunha quem em recente obra para se repensar o papel do direito natural na contemporaneidade, mas fazendo uso ainda mais restrito de $\mathrm{O}$ Anticristo do que fora feito por Verdross, afirma que autores como Nietzsche esvaziaram a justiça de sentido, preencheram-na de puro poder. Aduz ainda o autor que a partir desta abordagem não haverá esperanças para as vítimas da injustiça (Ferreira dA Cunha, 2013, p. 13). Nestes dois casos citados há uma simplicidade da leitura sobre o problema da justiça em Nietzsche, confundem a justiça com mero poder desmedido, ou como uma reação dos fracos em relação aos fortes.

\section{CONCLUSÃO}

Assim, a morte do direito natural seria apenas mais um capítulo da história da metafísica jurídica e como esta ideia ainda se mostra enquanto uma imagem fundamental para a tradição do direito. Invocar o direito natural, e seus congêneres metafísicos como dignidade humana, são modos de uma teologia jurídica disfarçada dentro do direito que se diz secularizado dentro do paradigma do estado de 
direito. Posição que por si é plenamente legítima, desde que honesta ao reafirmar a sua face teológica-metafísica. O paradoxo do direito contemporâneo ainda é entre um direito parcialmente secularizado e uma teologia jurídica metamorfoseada em um discurso pós-metafísico, que todavia continua sendo metafísica.

Certamente qualquer sugestão para a solução desse paradoxo está para além dos limites deste artigo e das nossas pretensões. $\mathrm{O}$ presente trabalho se dispôs tão somente a apresentar a posição de Nietzsche quanto ao direito natural e quais outros desenvolvimentos seriam passíveis a partir da própria filosofia nietzschiana. Os aspectos que merecidamente são interessantes na crítica de Nietzsche são: 1 - a contestação de um fundamento metafísico para o direito, seja o direito natural ou a antiga discussão quanto a justiça eterna. 2 - Em si a natureza não é justa ou injustiça, pois esta qualificação seria apenas um impulso de antropomorfização que está em todo imaginário cultura e, portanto, linguístico; assim como Hans Blumenberg conclui seus Paradigmas para uma metaforologia a partir de uma referência direta a aforismos póstumos de Nietzsche, quais sejam, "racionalidade ou irracionalidade não são predicados do universo" (NIETZsChe, 1999, Vol. 9, p. 502. KSA 9 11[157]), "sem nenhuma consideração formal, ética ou estética” (Nietzsche, 1999, Vol. 9, p. 528. KSA 9 11[225]). Podemos verificar em diálogo com estes dois filósofos que "metafísica se mostrou para nós como uma metafórica tomada ao pé da letra e a desaparição da metafísica chama novamente a metafórica a ocupar o seu lugar” (Blumenberg, 2013, p.189).

Podemos concluir a partir de Nietzsche que a própria expressão direito natural é uma contradição em termos se partirmos da oposição entre natureza e cultura, Physis e Nomos. Porquanto o que o direito - e também a própria filosofia - chama de natureza não é nunca o evento real, único e irrepetível, mas tão somente uma interpretação do próprio fenômeno dentro de marcos históricos muito delimitados a partir de um aparato técnico fornecido pela ciência do seu tempo. Portanto, integralmente contingente. $\mathrm{O}$ micro e macrocosmos são 
"natureza", mas foram completamente desconhecidos durante milênios da humanidade, portanto não existiam para o intelecto humano, mas mesmo assim existiram do ponto de vista fenomênico. Fenômenos estes que ainda hoje são ignorados por grande parcela da humanidade e existem independentemente do intelecto humano ou de um conjunto de crenças. Por sua vez, o que a tradição chamou de normatividade decorrente da "natureza" é tão somente um subproduto da cultura. Poderíamos chamar esse fenômeno de uma aporia do conceito de natureza.

\section{REFERÊNCIAS}

ADEODATO, João Maurício. Uma Teoria da Norma e do Direito Subjetivo numa Filosofia Retórica da Dogmática Jurídica. São Paulo: Universidade de São Paulo, Tese de Livre Docência, 2010.

ADEODATO, João Maurício. Uma Teoria Retórica da Norma Jurídica e do Direito Subjetivo. $2^{\text {a }}$ Ed. São Paulo, Noesis: 2014.

AHRENS, Heinrich. Naturrecht: oder Philosophie des Rechts und des Staates auf dem Grunde des ethischen Zusammenhanges von Recht und Kultur. Aalen: Scientia-Verl., 1968.

BENOIT, Blaise. A justiça como problema. Cad. Nietzsche, São Paulo, n. 26, p. 53-71, 2010.

BLUMENBERG, Hans. Arbeit am Mythos. Frankfurt am Main: Suhrkamp, 2006.

BLUMENBERG, Hans. Paradigmen zu einer Metaphorologie: Kommentar von Anselm Haverkamp. Frankfurt am Main: Suhrkamp Verlag, 2013. CARDOSO, Renato César. A ideia de justiça em Schopenhauer. Belo Horizonte: Argumentum, 2008.

CASANOVA, Marco Antônio. O instante extraordinário: vida, história e valor na obra de Friedrich Nietzsche. Rio de Janeiro: Forense Universitária, 2003.

CASANOVA, Marco Antônio. Eternidade frágil: ensaio de temporalidade na arte. Rio de Janeiro: Via Verita, 2013. 
CIORAN, Emil. Breviário de decomposição. Trad. José Thomaz Brum. Rio de Janeiro: Editora Rocco, 2011.

DURANTE, Felipe dos Santos. Virtude, direito, moralidade e justiça em Schopenhauer. Dissertação (mestrado) - Universidade Estadual de Campinas, Instituto de Filosofia e Ciências Humanas. Campinas: 2012.

EMDEN, Christian J. Nietzsche's Naturalism: Philosophy and the Life Sciences in the Nineteenth Century. Cambridge: Cambridge University Press, 2014.

FERREIRA DA CUNHA, Paulo. Rethinking Natural Law. Berlin: Springer, 2013.

FINNIS, John. Natural law and natural rights. Oxford: Oxford Univ. Press, 2011.

FLÜCKIGER, Felix. Geschichte des Naturrechtes. Zollikon-Zürich: Evang. Verl., 1954.

GROSSI, Paolo. Mitologias jurídicas da modernidade. Trad. Arno Dal Ri Júnior. Florianópolis: Fundação Boiteux, 2004.

HABERMAS, Jürgen. Auch eine Geschichte der Philosophie: Band 1: Die okzidentale Konstellation von Glauben und Wissen und Band 2: Vernünftige Freiheit. Spuren des Diskurses über Glauben und Wissen. Frankfurt am Main: Suhrkamp Verlag, 2019.

HEGEL, Georg Wilhelm Friedrich. Grundlinien der Philosophie des Rechts: oder Naturrecht und Staatswissenschaft im Grundrisse. Frankfurt am Main: Suhrkamp, 1976.

HEGEL, Georg Wilhelm Friedrich. Princípios da filosofia do direito. Trad. Orlando Vitorino. São Paulo: Martins Fontes, 1997.

HEIDEGGER, Martin. Caminhos de Floresta. Lisboa: Calouste Gulbenkian, 2002.

HERVADA, Javier. Síntesis de historia de la ciencia del derecho natural. Navarra: EUNSA, 2006.

KOPPERSCHMIDT, Josef; SCHANZE, Helmut (Org.). Nietzsche oder „Die Sprache ist Rhetorik“. München: Fink, Wilhelm, 1994.

LIMA LOPES, Reinaldo (Org.). Curso de História do Direito. São Paulo: Método, 2009. 
LOPES, Rogério. "A ambicionada assimilação do materialismo": Nietzsche e o debate naturalista na filosofia alemã da segunda metade do século XIX. Cad. Nietzsche, São Paulo, n. 29, 309-352, 2011.

LÖWITH, Karl. Nietzsche's Philosophy of the Eternal Recurrence of the Same. Berkeley: University of California Press, 1997.

LUHMANN, Niklas. Soziologische Aufklärung 1: Aufsätze zur Theorie sozialer Systeme. Westdeutscher Verlag: Opladen, 1970.

MARQUARD, Odo. Philosophie des Stattdessen: Studien. Stuttgart: Reclam, 2000.

MARQUARD, Odo. Zukunft braucht Herkunft: Philosophische Essays. Stuttgart: Reclam, 2015.

MENEZES, Djacir. Tratado de Filosofia do Direito. São Paulo: Atlas, 1980.

NIEMEYER, Christian (Org.). Diccionario Nietzsche: conceptos, obras, influencias y lugares. Madrid: Biblioteca Nueva, 2012.

NIETZSCHE, Friedrich. Sämtliche Werke: Kristische Studienausgabe. Edição crítica organizada por Mazzino Montinari e Giorgio Colli. Berlim: Walter de Gruyter, 1999. 15 volumes.

NIETZSCHE, Friedrich. Werke. Kritische Gesamtausgabe. Vol. II/4: Vorlesungsaufzeichnungen (WS 1871/72-WS 1874/75). Walter de Gruyter: Berlin, 1995.

NIETZSCHE, Friedrich. Assim Falou Zaratustra: Um livros para todos e para ninguém. Trad. Paulo César de Souza. São Paulo: Companhia das Letras, 2011.

NIETZSCHE, Friedrich. Aurora: Reflexões sobre os preconceitos morais. Trad. Paulo César de Souza. São Paulo: Companhia das Letras, 2001.

NIETZSCHE, Friedrich. Crepúsculo dos Ídolos: Ou como se filosofa com martelo. Trad. Paulo César de Souza. São Paulo: Companhia das Letras, 2006.

NIETZSCHE, Friedrich. Gaia Ciência. Trad. Paulo César de Souza. São Paulo: Companhia das Letras, 2001a.

NIETZSCHE, Friedrich. Genealogia da Moral: Uma polêmica. Trad. Paulo César de Souza. São Paulo: Companhia das Letras, 2001b. 
NIETZSCHE, Friedrich. Humano, demasiado Humano: Um livro para Espíritos livres. Trad. Paulo César de Souza. São Paulo: Companhia das Letras, 2001d.

NIETZSCHE, Friedrich. Humano, demasiado Humano II. Trad. Paulo César de Souza. São Paulo: Companhia das Letras, 2008.

NIETZSCHE, Friedrich. O Nascimento da Tragédia: Ou Helenismo e Pessimismo. Trad. Jacó Guinsburg. São Paulo: Companhia das Letras, 1999a. NIETZSCHE, Friedrich. Para além do bem e do mal: Uma filosofia para o futuro. Trad. Paulo César de Souza. São Paulo: Companhia das Letras, 2005. PASCHOAL, Antonio Edmilson. Nietzsche e o Ressentimento. São Paulo: Humanitas, 2015.

PATTARO, Enrico; ROVERSI, Corrado (Org.). A Treatise of Legal Philosophy and General Jurisprudence: Volume 12 - Legal Philosophy in the Twentieth Century: The Civil Law World, Tome 2: Main Orientations and Topics. Dordrecht: Springer, 2016.

POPPER, Karl R. Lógica das ciências sociais. Trad. Estevão de Rezende Martins; Apio Cláudio Muniz Acquarone Filho. Brasília: Universidade de Brasília, 1978.

ROMMEN, Heinrich A. The Natural Law: A Study in Legal and Social History and Philosophy. Trad. Thomas R. Hansley. Indianapolis: Liberty Fund, 1998.

SCHACHT, Richard. O naturalismo de Nietzsche. Cad. Nietzsche, São Paulo, v. 29, p. 35-75, 2011.

SCHOPENHAUER, Arthur. O Mundo como Vontade e como Representação. Trad. Jair Barbosa. São Paulo: UNESP, 2005.

SEDGWICK, Peter R. Nietzsche's Justice: Naturalism in Search of an Ethics. Montreal: McGill-Queen's University Press, 2013.

STRAUSS, Leo. Direito natural e história. Trad. Miguel Morgado. Lisboa: Edições 70, 2009.

TRUYOL SERRA, António. Esbozo de una Sociologia del Derecho Natural. Revista de Estudios Politicos, Madrid, vol. XXIV, 1949.

VERDROSS, Alfred. Filosofia del derecho del mundo occidental: vision panoramica de sus fundamentos. Cidade do México: UNAM, 1962. 
WILLIAMS, Robert R. Tragedy, Recognition, and the Death of God: Studies in Hegel and Nietzsche. Oxford: Oxford, 2012.

WOTLING, Patrick. Quando a potência dá prova de espírito: origem e lógica da justiça segundo Nietzsche. Cad. Nietzsche, São Paulo, n.32, pp. 203-232, 2013.

\section{LUIZ FILIPE ARAÚJO ALVES}

Professor Adjunto de Filosofia do Direito e Teoria do Direito na Universidade Federal de Viçosa. Graduado em Direito pela Universidade Federal de Viçosa, Mestre e Doutor em Direito pela Faculdade de Direito e Ciências do Estado da Universidade Federal de Minas Gerais. Estágios de pesquisa doutoral na Paris-Lodron-Universität Salzburg/Áustria e de pesquisas pós-doutorais na Faculdade de Direito de Vitória e na Christian-Albrechts-Universität zu Kiel/ Alemanha. Coordenador do Grupo de Estudos e Pesquisa HERETHIK - "Hermenêutica, Retórica e Ética" na Universidade Federal de Viçosa.

Endereço profissional: Universidade Federal de Viçosa - Departamento de Direito - s/n, Campus Universitário, Viçosa - Minas Gerais, 36570-900, Brasil.

ORCID ID: https://orcid.org/0000-0003-0224-9638

E-mAIL: luiz-filipe@ufv.br

Recebido: 23/04/2020

Aceito: $15 / 10 / 2020$ 


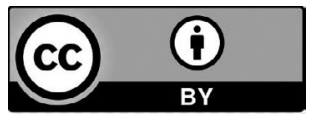

Este trabalho está licenciado sob uma licença Creative Commons Attribution 4.0 International License.

Autores e autoras cedem à Revista Sequência direitos exclusivos de primeira publicação, ficando o trabalho licenciado sob a Creative Commons Attribution 4.0 International License. A licença autoriza que terceiros remixem, adaptem e ou criem a partir do trabalho publicado, indicando o crédito ao trabalho original e sua publicação inicial. Os autores têm permissão para assumir contratos adicionais em separado, com distribuição não exclusiva da versão publicada na Revista Sequência, indicando, de todo modo, a autoria e publicação inicial neste periódico. 